\title{
Allocution de Monseigneur Bernard Hubert, évêque de Saint-Jean-Longueuil
}

\section{Bernard Hubert}

Volume 51, 1984

URI : https://id.erudit.org/iderudit/1007453ar

DOI : https://doi.org/10.7202/1007453ar

Aller au sommaire du numéro

Éditeur(s)

Les Éditions Historia Ecclesiæ Catholicæ Canadensis Inc.

ISSN

0318-6172 (imprimé)

1927-7067 (numérique)

Découvrir la revue

Citer ce document

Hubert, B. (1984). Allocution de Monseigneur Bernard Hubert, évêque de Saint-Jean-Longueuil. Sessions d'étude - Société canadienne d'histoire de l'Église catholique, 51, 81-86. https://doi.org/10.7202/1007453ar

Tous droits réservés @ Les Éditions Historia Ecclesiæ Catholicæ Canadensis Inc., 1984
Ce document est protégé par la loi sur le droit d'auteur. L'utilisation des services d'Érudit (y compris la reproduction) est assujettie à sa politique d'utilisation que vous pouvez consulter en ligne.

https://apropos.erudit.org/fr/usagers/politique-dutilisation/ 


\section{Allocution de Monseigneur Bernard Hubert, évêque de Saint-Jean-Longueuil}

La Société canadienne d'histoire de l'Église catholique tient aujourd'hui son cinquante-et-unième congrès annuel. Vous avez choisi de venir dans le diocèse de Saint-Jean-Longueuil pour cet événement. J'ai ouï-dire qu'une des raisons motivant ce choix était que notre Église diocésaine vivait elle aussi sa cinquante-et-unième année d'existence. Votre société et notre diocèse ont été tous les deux fondés en 1933.

\section{LE CONGRÈS DE LA S.C.H.E.C. ET L'ÉGLISE DE SAINT-JEAN-LONGUEUIL}

Cinquante ans dans la vie de l'Église universelle, c'est bien peu! Malgré une population considérable, le diocèse de Saint-Jean-Longueuil se sent petit. Il est encore dans l'âge de l'adolescence si on le compare aux Églises plus anciennes. La brièveté de notre histoire invite à l'humilité. Et pourtant, la vie chrétienne n'est pas moins intense ici que dans les autres diocèses.

L'Église de Saint-Jean-Longueuil connaît une vitalité extraordinaire. Les défis apportés par la rapide urbanisation du territoire et une démographie galopante sont relevés avec audace et succès. Les communautés chrétiennes sont jeunes et vivantes. Leurs pasteurs voient leur action évangélisatrice multipliée plusieurs fois grâce à un nombre considérable de laïcs qui ont pris au sérieux la responsabilité de leur baptême. Même s'il est jeune, notre diocèse est présent en de multiples endroits de l'Église universelle par les missionnaires et les coopérants oeuvrant là-bas en notre nom.

Vous avez pris comme thème de votre congrès: 300 ans de présence religieuse. Malgré son jeune âge, notre diocèse revendique un pareil titre. Chambly, La Prairie, Boucherville, Kahnawake, Longueuil et quelques 
autres municipalités ont constitué des communautés chrétiennes depuis trois siècles. Les travaux historiques portant sur notre milieu ainsi que l'exposition d'art sacré présentée durant votre rencontre en témoignent éloquemment. Notre diocèse est récent et parfois effervescent mais notre patrimoine est ancien et riche.

Je fais l'éloge de ce diocèse pour établir un parallèle au crédit que j'accorde à la Société canadienne d'histoire de l'Église catholique. Elle aussi a cinquante ans. C'est bien peu à comparer avec les titres de nobiesse de certaines grandes académies ou sociétés qui plongent leurs racines loin dans le temps. Et pourtant, les travaux réalisés dans votre groupe ne sont pas de moindre qualité que ceux publiés ailleurs. Les chercheurs de la S.C.H.E.C. sont compétents et leurs oeuvres dégagent avec clarté les faits de l'histoire et les leçons du passé. Je vous dis ma gratitude d'être venus porter votre témoignage dans l'Église de Saint-Jean-Longueuil. Votre action éclaire nos origines, nourrit notre fierté et stimule notre responsabilité.

À cet égard, il m'est très agréable de souligner l'existence de plusieurs sociétés d'histoire dans notre région. Elles sont si nombreuses qu'il serait hasardeux de vouloir toutes les nommer de mémoire. Un nombre important de femmes et d'hommes y participent. Quelques-uns sont des universitaires. D'autres sont des historiens formés par l'action. Une activité intense manifeste le dynamisme de ces sociétés. La publication régulière de monographies, la présentation visuelle de lieux et de résidences historiques par des plaques d'identification, les échanges enrichissants des cercles d'études et des rencontres inter-sociétés remplissent les annales de nos sociétés d'histoire.

À quelques reprises, j'ai eu l'occasion de lire ou de voir les travaux réalisés dans ces groupes. La qualité est manifeste. Comptes rendus de recherches brèves, travaux de longue haleine, exposés de sensibilisation au patrimoine se succèdent, révélant chaque fois le même souci d'objectivité et de sérieux. Cette action fait rarement les manchettes. Il faut s'arrêter et prêter l'oreille à ce qui émane des divers groupes intéressés à l'histoire locale pour découvrir progressivement ce qui se fait dans ce domaine. Notre région fourmille d'humbles chercheurs tenaces et de fidèles chroniqueurs compétents. Toutes ces personnes ont un apport social extrêmement riche. À leur manière, elles sont des forces vives dans le milieu. Elles contribuent à la sensibilisation des citoyens à leur patrimoine culturel. Il n'est pas étonnant que beaucoup de gens de chez nous soient fiers de leur appartenance et connaisseurs de leur héritage. 


\section{L'HISTOIRE ET L’AVENIR DE LA SOCIÉTÉ QUÉBÉCOISE}

Ces témoins de notre vie collective risquent cependant de passer à une élite locale qui n'aura pas beaucoup de liens avec l'ensemble de la société dans l'avenir. Un très grand nombre de contemporains sont des migrants qui envahissent la région métropolitaine de Montréal, s'y installent sans s'y fixer et vivent surtout du temps présent. Ils sont le reflet fidèle du monde dans lequel nous venons d'entrer. Des changements profonds bouleversent le milieu. Les institutions elles-mêmes sont touchées. Qui d'entre nous n'est pas conscient de la fracture qui blesse le mariage et la famille. L'école et la ville qui ont toujours été des facteurs importants de socialisation sont marquées par l'anonymat et le désengagement. Loin d'être principalement économique, la crise de notre société rejoint en profondeur les institutions et les valeurs qui ont façonné notre histoire et notre culture.

Qui plus est, nous sommes bousculés jusque dans nos méthodes de travail. Écoutez ce que disent les nouveaux maîtres à penser. Ils ne parlent que d'informatique, de robotique, de bureautique. Ces techniques pénètrent non seulement les milieux de travail mais aussi le monde de l'éducation et l'univers familial. Avant longtemps, vous et moi serons devenus des analphabètes par rapport aux nouveaux langages et des ignares à côté des techniciens transformés en apprentis sorciers. Je ne dramatise pas. Les nouvelles technologies changent profondément la vie des personnes et des sociétés. Les conséquences sont mal connues mais sûrement énormes. En particulier, ces méthodes de travail sont coupées radicalement de celles du passé. Comment assurer alors une continuité avec nos origines, le passage de l'héritage à des gens immergés dans un univers culturel tout autre?

Ce qui est menacé par ce raz-de-marée électronique, c'est l'avenir de la liberté. De toutes les définitions de la liberté, celle de Bergson me plait davantage. Ce philosophe français dit de la liberté qu'elle est la capacité de récupérer tout son passé afin de l'engager totalement dans son avenir. Cela est beau. Est libre la personne qui peut disposer de tous les éléments de son être et s'en sert effectivement pour se réaliser pleinement. Il n'y a donc pas d'avenir valable sans investissement des germes venus du passé. Même si les technologies nouvelles sont là pour rester et qu'elles contribueront sûrement à un progrès de nos sociétés, elles ne pourront à elles seules assurer la liberté de notre peuple. Il nous faut favoriser cette liberté par des liens entre l'héritage et le projet.

Quel trait d'union peut ménager aujourd'hui semblable liberté? Ce sont les personnes et les groupes qui connaissent bien la valeur du passé et qui sont aptes à faire jaillir le bien patrimonial dans les réalités d'aujourd'hui. 
Lorsque vous nous sensibilisez au contenu et à l'évolution de l'histoire. que vous publiez des monographies sur les familles ancestrales et leur vie collective, que vous faites le portrait du temps jadis et des richesses tant matérielles que morales que celui-ci nous a léguées, vous ramassez tout ce qui est notre passé et vous le mettez en disponibilité pour notre avenir. On dit souvent que l'histoire est maitresse de vie. Cela est vrai parce que les historiens nous permettent, grâce à leurs travaux, de tisser des liens entre l'héritage et le projet. Ils nous invitent à la liberté qui est récupération de noire passé pour engager ce dernier dans notre avenir.

À Québec, en septembre 1984, Jean-Paul II disait de la culture qu'elle est la «recherche fondamentale du beau, du vrai, du bien, qui exprime au mieux l'homme, comme le sujet porteur de la transcendance de la personne, qui l'aide à devenir ce qu'il doit être et pas seulement à se prévaloir de ce qu'il a ou de ce qu'il possède». Les sociétés d'histoire participent à ce courant caractéristique et éducateur de l'homme. Dans un monde de l'instantané, de l'image et du provisoire, les travaux que vous faites permettent de dégager les forces vives dans l'histoire et la culture. Ils nous aident tous à trouver notre identification et à nous insérer dans le lieu et le temps que constitue l'histoire. À cause des forces de dissolution sociale existant aujourd'hui, vous constituez un service essentiel au sens où on l'entend à l'occasion des conflits de travail dans les mondes public et parapublic. Vous jouez un rôle extrêmement important dans l'élaboration d'un avenir de liberté et dans la survie de notre peuple.

\section{LA CULTURE ET LA FOI CHRÉTIENNE}

Pour nous, parler d'avenir et de survie, c'est aussi évoquer la place de la foi chrétienne chez nous. Des liens intimes existent entre foi et culture. Dans tous les peuples, le développement de la culture s'est toujours fait dans une interaction avec les croyances religieuses. Briser la symbiose de ces deux réalités, c'est couper un peuple de son histoire, le priver de son environnement vital. Jean-Paul II qui s'intéresse grandement à la culture nous a dit des choses très pertinentes à ce sujet lors de son séjour parmi nous. La foi apporte beaucoup à la culture, disait-il. La croyance de la foi éclaire le sens et le contenu de la culture. À la manière du sel dans les aliments, la première donne de la saveur à la seconde. Elle la soulève et lui donne de l'ampleur. L'image que l'on a de Dieu influence celle que l'on se fait de l'homme. La foi questionne la culture en lui demandant, par exemple, quelles sont les valeurs poursuivies dans cette recherche fondamentale qui vise à aider l'homme à devenir ce qu'il doit être, quel destin assurera un bonheur vrai et durable, quelle place un peuple est prêt à faire aux pauvres et aux déshérités? 
Réciproquement, la culture permet à la foi de s'incarner. Pourquoi le christianisme est-il si identifié à l'Occident si ce n'est parce que notre culture, dominante dans le monde depuis des siècles, a donné à Jésus ressuscité notre visage. C'est à travers la culture que le Christ, Homme universel depuis sa résurrection, est indien, québécois, latino américain et autre. Le Sauveur est concret et visible à travers nos manières de vivre, de penser et d'agir. Ainsi, ce sont des moeurs familiales et paroissiales qui ont permis aux chrétiens d'ici de pratiquer la charité évangélique dans les corvées, la guignolée, l'accueil et l'hospitalité, l'asile et l'adoption. Quand nous nous arrêtons pour prendre conscience de notre identité, force nous est de constater que le christianisme est également notre identité spirituelle et notre identité culturelle. Dans ce temps de sécularisation, n'avons-nous pas à nous demander ensemble ce qu'il advient de notre héritage?

Il y a un autre aspect important de la relation foi et culture, c'est celui de l'action de la foi dans le multiculturalisme. Par définition, la culture identifie, caractérise, sépare les groupes humains. On peut même dire que les cultures sont étanches. La communication d'une culture à une autre est difficile. Nous savons par exemple que dans un même quartier urbain Anglophones et Francophones peuvent habiter côte à côte pendant des années sans jamais vraiment frayer. Les univers culturels amènent souvent le repli sur soi. Ils sont alors des lieux propices à l'intolérance, au racisme, au sentiment de supériorité par rapport à autrui. La foi chrétienne critique des attitudes semblables. Comme le rappelait Jean-Paul II à Winnipeg, le commandement nouveau apporté par le Christ propose d'ouvrir les cultures pour en faire des champs de communion.

Notre société pluraliste risque de devenir un terrain de conflits et d'injustices si nous n'y apportons pas l'évangile. La fierté des origines est légitime. L'affirmation de soi est nécessaire pour atteindre son épanouissement. Toutefois la rencontre de sa propre culture avec des façons de vivre façonnées tout autrement par l'histoire crée un rapport de force qui peut dégénérer en domination-oppression, en orgueil-mépris. Seul l'amour mutuel demandé par l'évangile permet de dépasser ce cadre dialectique. Aimer son prochain comme soi-même signifie que l'estime que l'on a de soi est telle que l'on peut s'ouvrir à autrui, lui faire confiance, l'aimer dans la communion et le partage. La foi chrétienne invite à avoir une fierté profonde et rayonnante par rapport à soi et, en même temps, à l'accueil et à l'amour des personnes différentes parce qu'issues d'une autre culture. Sans être une mosaïque à l'américaine, notre pays est quand même marqué par le multiculturalisme. Nous pouvons en faire un lieu de méfiance, d'affrontement et d'intolérance ou bien une terre de concorde, de paix et de solidarité. 
C'est dans la mesure où la foi et la culture vont continuer de s'imbriquer que nous pourrons réaliser l'unité morale qui est nécessaire à toute société heureuse et féconde. Quels que soient les défis rencontrés dans la culture, la foi chrétienne vient toujours comme une Bonne Nouvelle. Même si dans l'histoire les chrétiens ont souvent imposé leurs vues et leurs intérêts, l'évangélisation authentique vise non pas l'assujettissement des individus et la mainmise cléricale sur le bien commun mais la libération des personnes et le développement du Royaume au coeur des réalités humaines. L'ambiguité marque toujours la marche de l'histoire. Néanmoins, ce que nous avons de meilleur en nous est venu de la rencontre du peuple que nous sommes avec l'Église du Christ. Que serions-nous si dès les temps de la colonie de la Nouvelle-France jusqu'à nos jours la Bonne Nouvelle de l'évangile n'avait soutenu, éclairé, structuré notre vie collective, nos luttes politiques, la survivance française, les institutions d'enseignement, de loisir, de santé et de service social?

La foi chrétienne est enracinée dans l'héritage reçu. Notre peuple aurait tout avantage qu'elle soit aussi le ferment de nos projets. Bien sûr, l'avenir sera fort différent de ce que nous avons vécu dans le passé. Déjà, sur le plan des institutions, les aménagements sont la responsabilité de l'État. Celui-ci voit à ce que les services soient offerts aux citoyens quelles que soient leurs caractéristiques ethniques, linguistiques ou religieuses. Cela est normal. Le défi de tous est de donner une âme, un esprit à une société qui devient de plus en plus hétérogène par la venue de nombreux immigrants apportant ici de nouvelles cultures et par la cohabitation sociale de groupes aux options diversifiées. Les valeurs de l'évangile sont de nature à ouvrir les mentalités dans le sens du respeet mutuel et de l'enrichissement réciproque. Notre histoire montre le rôle vital qu'a joué la foi chrétienne chez nous. L'avenir, me semble-t-il, passe aussi par la voie de l'imbrication foi et culture. Si nous voulons poursuivre une telle oeuvre, je vous rappelle que la collaboration des historiens est nécessaire. Par vos travaux, vous nous aidez à comprendre de manière exacte les liens passés entre foi et culture et, ainsi, vous éclairez les chemins de l'avenir.

\section{$* * *$}

En terminant, je formule le voeu que la rencontre des membres de la Société canadienne d'histoire de l'Église catholique avec les personnes actives dans les sociétés historiques de notre milieu soit source de stimulant et de joie pour chacun. Pour ma part, votre présence chez nous me rappelle que nous formons tous ensemble une communauté de destin que vous et moi avons à assumer dans la joie et l'espérance. Avec gratitude et admiration, je vous dis ma solidarité. Je vois en vous des agents de libération dans le témoignage que vous rendez à la vérité de l'histoire et à la vérité de la foi. 